http://jmscr.igmpublication.org/home/ ISSN (e)-2347-176x ISSN (p) 2455-0450

crossref DOI: https://dx.doi.org/10.18535/jmscr/v8i2.39

\title{
Morning Glory Disc Anomaly- A Rare Case Report
}

\author{
Authors \\ Deepthi Janga $^{1 *}$, Deepthi Pullepu ${ }^{2}$, V Murali Krishna ${ }^{3}$ \\ Rangaraya Medical College, Kakinada \\ *Corresponding Author \\ Dr Deepthi Janga \\ Department of Ophthalmology, Rangaraya Medical College, Kakinada, India
}

\section{Abstract}

- The morning glory disc anomaly is a congenital excavation of the posterior globe that involves the optic disc.

- Although mistakenly referred to as a variant of optic disc coloboma, the morning glory disc anomaly is truly a distinct anomaly, as evidenced by its sporadic occurrence, its lack of association with iris or retinal colobomas, and its systemic associations.

- Here we discuss a case of 14 yrs old presented to our ophthalmology department with left eye morning glory disc anomaly

Keywords: Morning glory disc anomaly, Morning glory syndrome, Excavation.

\section{Introduction}

- In 1970 Kindler described an usual disc anomaly as morning glory disc because of its resemblance to morning glory flower

- Sporadic with Incidence 1:10 million

- More common in females

- Hypothesized to be failure of fusion of fetal fissures or primary mesenchymal abnormality

- It is characterised by U/L enlarged funnel shaped excavation that incorporates disc, blood vessels are increased in number and appears to be arising radially from the disc rather than usual central branching patter

- If associated with systemic features called as "Morning Glory Syndrome"
Systemic associations includes-

1) Trans sphenoidal encephalocele

2) Occult basal encephalocele

3) Hypoplasia of ipsilateral intracranial vasculature

4) Pan hypopituitorism

5) PHACE syndrome- Posterior fossa malformations

Hemangiomas

Arterial lesions

Cardiac abnormalities

Eye abnormalities

\section{Case Report}

A 14 yrs old female patient presented with decreased vision in Left eye since childhood. Child mother reports that left eye occasionally turned inwards, child seems to ignore people when they approach from left side 


\section{On examination}

1. Visual Acuity $6 / 6$ in the right eye CF 2 metres left eye

2. Pupil - left afferent pupillary defect (RAPD) rest of the anterior segment examination is normal in both eyes

\begin{tabular}{|l|c|c|}
\hline & OD & OS \\
\hline UCVA & $6 / 6$ & CF 2 meters \\
\hline BCVA & $6 / 6$ & $\begin{array}{l}-5.50 \mathrm{SPH} /+2.00 \\
\times 90^{\circ} \mathrm{CYL}-6 / 36\end{array}$ \\
\hline Retinoscopy & +0.50 & $-6.00+2.00 \times 90$ \\
\hline IOP & $14 \mathrm{mmHg}$ & $16 \mathrm{mmHg}$ \\
\hline Axial length & $20.89 \mathrm{~mm}$ & $23.60 \mathrm{~mm}$ \\
\hline $\begin{array}{l}\text { Anterior } \\
\text { segment }\end{array}$ & $\begin{array}{c}\text { Pupil -reacting to } \\
\text { light Rest - Normal }\end{array}$ & $\begin{array}{c}\text { Pupil - RAPD } \\
+ \text { Rest - normal }\end{array}$ \\
\hline
\end{tabular}

\section{Other System Examination}

- Vitals are stable

- CNS and Cranial nerves - normal

- CVS - Heart sounds normal ,no murmers

- Respiratory system- normal vesicular breath sounds heard

- Per Abdomen - soft ,no organomegaly

- ENT \& Dental - appeas to be normal

\section{Fundus}

RE normal fundus picture

LE

Media - clear

Optic disc is slightly enlarged, with multiple anomalous vessels radiating circumferentially A tuft of white material obscures the central cup There is a wide area of peripapillary pigment abnormality

\section{Retinoscopy}

Following cycloplegia with $2.5 \%$ phenylephrine and $1 \%$ cyclopentolate eye drops

+0.50 in the right eye

$-6.00+2.00 \times 90$ in the left eye.

2.PMT

Subjective Testing

RE $\quad 6 / 6$

$\mathrm{LE} \quad-5.50 \mathrm{SPH} /+2.00 \times 90^{\circ} \mathrm{CYL}-6 / 36$

\section{Investigations}

\section{B SCAN}

Conical excavation at posterior pole in to which optic disc is funneled out
2. Visual fields $30-2$

RE-Normal

LE- Enlargement of blind spot

\section{MRI}

- Scan of the orbit, sinuses, brain with gadolinium is ordered to exclude a transphenoidal encephalocele and intracranial carotid artery dysgenesis

- Neuroimaging results appears to be normal

- Intra cranial vascular system is normal
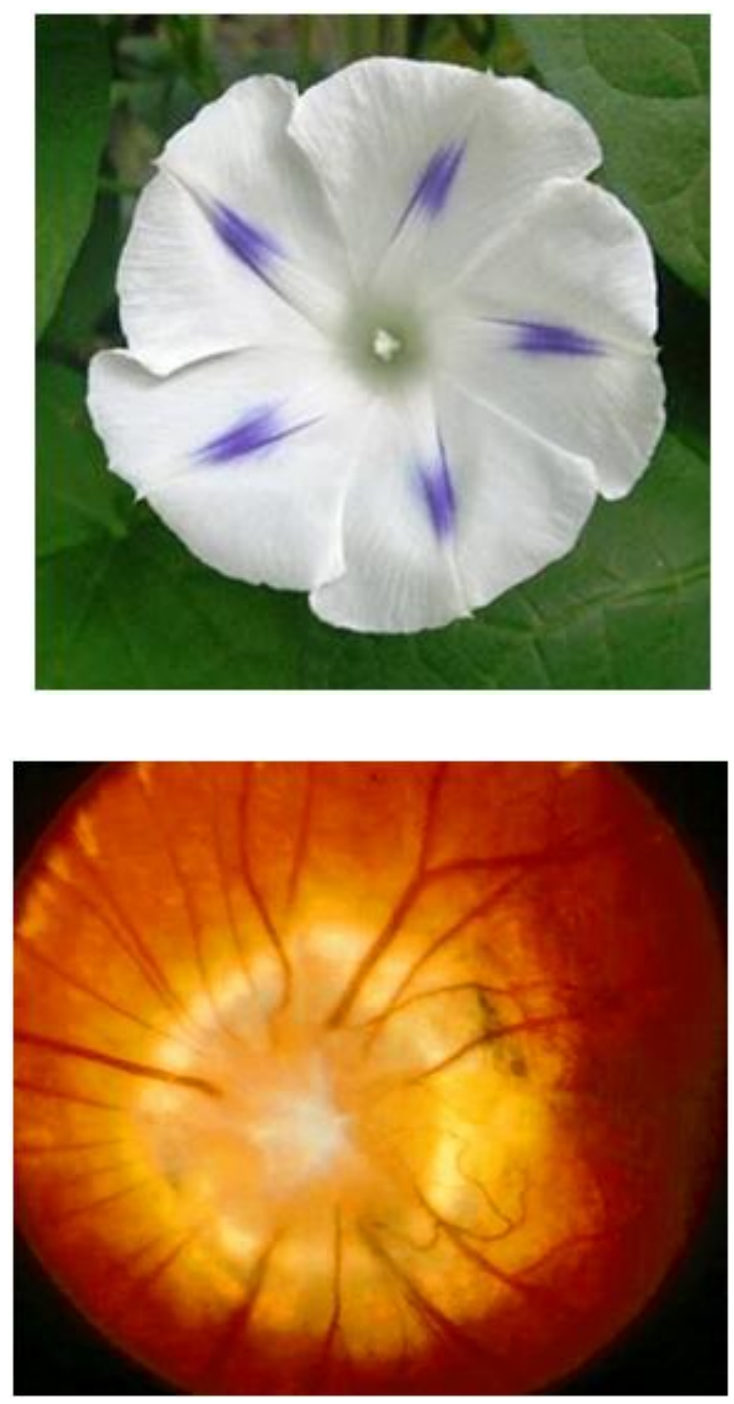

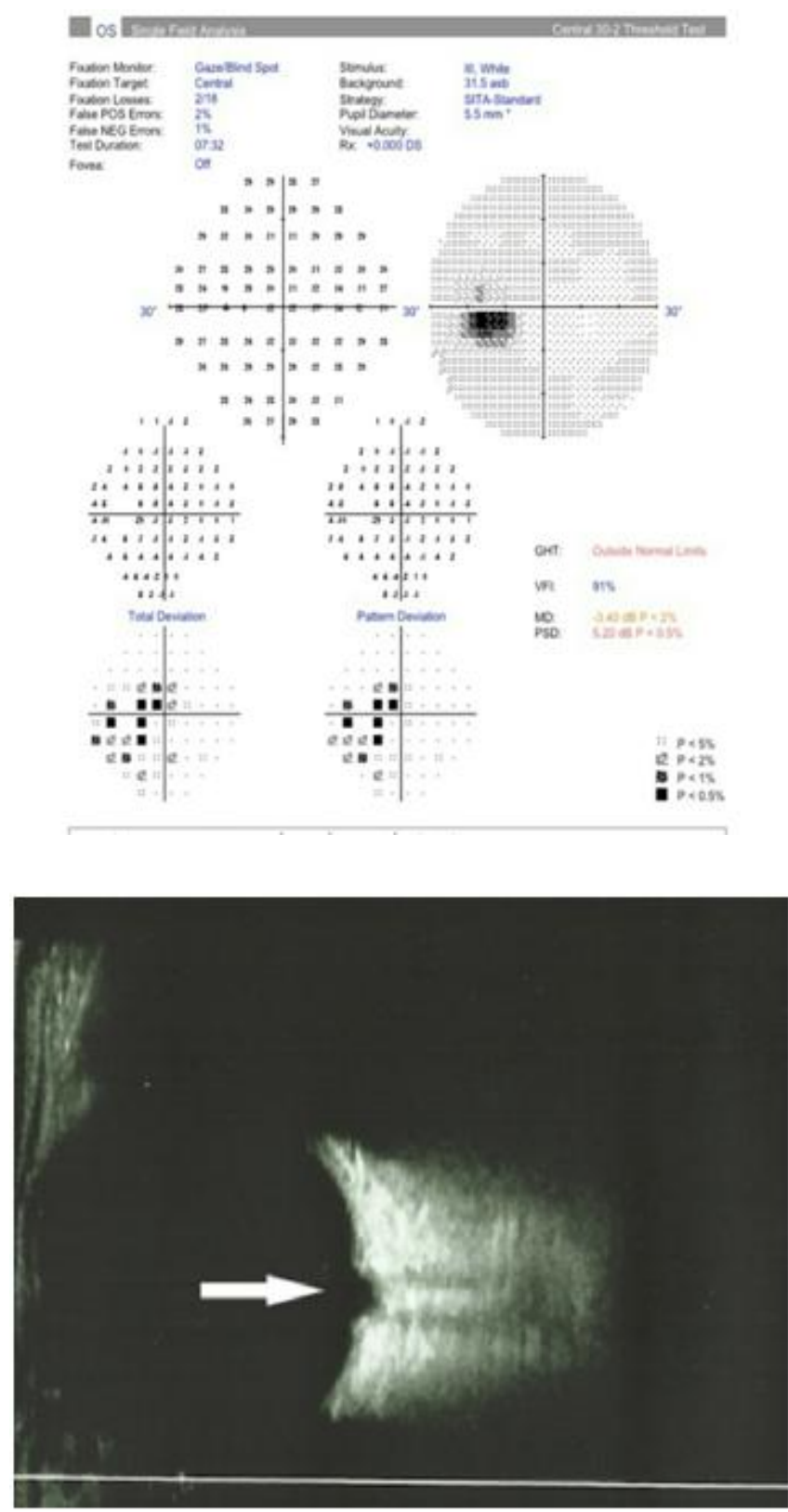

\section{Management}

- The child is prescribed full-time glasses wear to correct the anisometropia and parttime patching of the better eye 6 hours patching per day

- Discussion with her mother includes the diagnosis and the news that, despite the glasses and patching, the overall visual prognosis is poor.

- She is scheduled for regualr follow up visit in view of amblyopia and retinal detachment

- Referred to a pediatric otolaryngologist for evaluation of the soft palate

\section{Conclusion}

- The visual prognosis in individuals with morning glory disc anomaly is poor

- In addition to the abnormal disc itself, there is an added compounding variable of high refractive errors, amblyopia, and strabismus, Retinal detachment

- Although ocular realignment surgery and treatment of anisometropic amblyopia is recommended and may result in some recuperation of vision, it is rare to see dramatic improvements

\section{References}

1. Muslubas IS, Hocaoglu M, Arf $S$ \& Karacorlu M. A case of morning glory syndrome associated with persistent hyperplastic primary vitreous and Peters' anomaly. GMS Ophthalmology Cases. 2017;

https://www.ncbi.nlm.nih.gov/pmc/articles /PMC5244077/.

2. Morning Glory Syndrome. Orphanet. 2017; http://www.orpha.net/consor/cgibin/Disease_Search.php?lng=EN\&data_id $=10399$.

3. Strominger MB. Morning Glory Syndrome. American Academy of Ophthalmology. October 14, 2015; https://www.aao.org/pediatric-centerdetail/neuro-ophthalmology-morningglory-syndrome. 